\title{
A cross-sectional study on health differences between rural and non-rural U.S. counties using the County Health Rankings
}

\author{
Timothy J. Anderson ${ }^{1 *}$, Daniel M. Saman ${ }^{1}$, Martin S. Lipsky³ and M. Nawal Lutfiyya ${ }^{2}$
}

\begin{abstract}
Background: By examining 2013 County Health Rankings and Roadmaps data from the University of Wisconsin and the Robert Wood Johnson Foundation, this paper seeks to add to the available literature on health variances between United States residents living in rural and non-rural areas. We believe this is the first study to use the Rankings data to measure rural and urban health differences across the United States and therefore highlights the national need to address shortfalls in rural healthcare and overall health. The data indicates that U.S. residents living in rural counties are generally in poorer health than their urban counterparts.

Methods: We used 2013 County Health Rankings data to evaluate differences across the six domains of interest (mortality, morbidity, health behaviors, clinical care, social and economic factors, and physical environment) for rural and non-rural U.S. counties. This is a cross-sectional study employing chi-square analysis and logit regression.

Results: We found that residents living in rural U.S. counties are more likely to have poorer health outcomes along a variety of measurements that comprise the County Health Rankings' indexed domains of health quality. These populations have statistically significantly $(p \leq 0.05)$ lower scores in such areas as health behavior, morbidity factors, clinical care, and the physical environment. We attribute the differences to a variety of factors including limitations in infrastructure, socioeconomic differences, insurance coverage deficiencies, and higher rates of traffic fatalities and accidents.

Discussions: The largest differences between rural and non-rural counties were in the indexed domains of mortality and clinical care.

Conclusions: Our analysis revealed differences in health outcomes in the County Health Rankings' indexed domains between rural and non-rural U.S. counties. We also describe limitations and offer commentary on the need for more uniform measurements in the classification of the terms rural and non-rural. These results can influence practitioners and policy makers in guiding future research and when deciding on funding allocation.
\end{abstract}

Keywords: Rural health, Health outcomes, Rurality, County Health Rankings

\section{Background}

There are differences in health, access to and the quality of healthcare between rural and urban areas in the United States [1]. Despite the various methods of classifying what constitutes a rural or urban location [2], studies continue to find that differences in health and the health care of rural populations and their urban peers are real [3-6]. Place is an essential

\footnotetext{
* Correspondence: tanderson@eirh.org

${ }^{1}$ Essentia Institute of Rural Health, 502 E. 2nd Street, Duluth, MN 55805, USA Full list of author information is available at the end of the article
}

variable in determining disparities between different populations $[1,7]$. We used the County Health Rankings (CHR), a project created by the University of Wisconsin Population Health Institute and the Robert Wood Johnson Foundation [8] to further examine the importance of place with regard to health outcomes. The CHR model is framed on the interconnectedness between health outcomes and health factors with policies and programs at the local, state, and federal level. Health factors measure the population health of a county and are comprised of weighted data on (1) 
health behaviors, (2) clinical care, (3) social and economic factors and the (4) physical environment. The following measures make up the health factors that influence the health outcomes of mortality and morbidity. Table 1 further details the CHR model and includes data sources.
(1) Health behaviors are measured by tobacco use, diet and levels of exercise, sexual activity and the use of alcohol and drugs.

(2) Clinical care is measured by access to and quality of care.

Table 1 County Health Rankings Model: Measures and Data Sources

\begin{tabular}{|c|c|c|}
\hline & Measure & Data source \\
\hline \multicolumn{3}{|l|}{ Health outcomes } \\
\hline Mortality $50 \% *$ & Premature death & National center for health statistics \\
\hline \multirow[t]{4}{*}{ Morbidity $50 \%$} & Poor or fair health & Behavioral risk factor surveillance system \\
\hline & Poor physical health days & Behavioral risk factor surveillance system \\
\hline & Poor mental health days & Behavioral risk factor surveillance system \\
\hline & Low birth weight & Behavioral risk factor surveillance system \\
\hline \multicolumn{3}{|l|}{ Health factors } \\
\hline \multicolumn{3}{|l|}{ Health behaviors (30 \%) } \\
\hline Tobacco use & Adult smoking & Behavioral risk factor surveillance system \\
\hline \multirow[t]{2}{*}{ Diet \& exercise } & Adult obesity & National center for chronic disease prevention and health promotion (NCCDPHP) \\
\hline & Physical inactivity & NCCDPHP \\
\hline Alcohol \& drug use & Excessive drinking & Behavioral risk factor surveillance system \\
\hline \multirow[t]{2}{*}{ Sexual activity } & STI data & National center for HIV/AIDS, viral hepatitis, STD, and TB prevention \\
\hline & Teen births & National center for health statistics \\
\hline \multicolumn{3}{|l|}{ Clinical care (20 \%) } \\
\hline \multirow[t]{3}{*}{ Access to care } & Uninsured & Small area health insurance estimates \\
\hline & Primary care physicians & HRSA area resource file \\
\hline & Dentists & HRSA area resource file \\
\hline \multirow[t]{3}{*}{ Quality of care } & Preventable hospital stays & Medicare/dartmouth institute \\
\hline & Diabetic screening & Medicare/dartmouth institute \\
\hline & Mammography screening & Medicare/dartmouth institute \\
\hline \multicolumn{3}{|l|}{ Social economic factors (40 \%) } \\
\hline \multirow[t]{2}{*}{ Education } & High school graduation & Data.gov, supplemented w/ national center for education statistics \\
\hline & Some college & American community survey \\
\hline Employment & Unemployment & Bureau of labor statistics \\
\hline Income & Children in poverty & Small area income and poverty estimates \\
\hline \multirow[t]{2}{*}{ Family and social support } & Inadequate social support & Behavioral risk factor surveillance system \\
\hline & Children in single parent households & American community survey \\
\hline \multirow[t]{2}{*}{ Community safety } & Violent crime & FBI Uniform crime reporting \\
\hline & Injury deaths & CDC Wonder \\
\hline \multicolumn{3}{|l|}{ Physical environment (10 \%) } \\
\hline \multirow[t]{2}{*}{ Air and water quality } & Air pollution - particulate matter & CDC Wonder \\
\hline & Drinking water violations & Safe drinking water information system \\
\hline \multirow[t]{3}{*}{ Built environment } & Limited access to health foods & USDA food environment atlas \\
\hline & Fast food restaurants & County business patterns \\
\hline & Access to recreational facilities & County business patterns \\
\hline
\end{tabular}

Policies and Programs

Federal, state and local programs believed to target health outcomes directly or attribute to health factors which cause outcomes

*Percentages indicate weights based on comparative importance within an outcome/factor and data quality 
(3) Social and economic factors are measured by education, employment, income, family and social support, and community safety.

(4) Physical environment consists of air and water quality as well as built environment data (access to healthy foods and recreational facilities).

The literature supports evidence of rural and urban differences in many of the health factors measured by CHR. Health behavior research indicates that both adolescents and adults in rural areas are more likely to smoke $[9,10]$. Moreover, rural children over the age of five are more likely to be obese or overweight [11], as are rural adults [12]. Rural residents consume fewer fruits and vegetables [13], and have greater rates of alcohol addiction and consumption than in urban locations [14]. Levels of physical activity are also higher in urban areas, with physical inactivity being higher in rural locations, particularly in the American South [15].

Clinical care research indicates that often there is a shortage in resources available to rural residents. Rural citizens in the United States are less likely to have health insurance as compared to suburban residents [16]. The Centers for Disease Control and Prevention (CDC) reports that rural citizens have fewer medical specialists per 100,000 people, including less pediatricians, obstetricians/gynecologists, and internists. Only the number of general and family physicians increase along the rural gradient [9]. Dental problems such as tooth loss increase along the urban-rural gradient [17], owing in part to a lack of dentists and dental visits [9]. Regarding quality of care, studies have shown that rural residents have a higher proportion of preventable hospital stays for acute and chronic conditions $[18,19]$.

While a complete analysis of the economic and social situation for rural residents would be a separate piece entirely, we do see evidence that while there has been an increase in rural children attending college [20], urban residents are still broadly more likely to have a bachelor's degree [21]. High school dropout rates may be similar for the two cohorts [22], as deeply rural and urban areas both suffer from systemic poverty [23].

Physical environment is the final of the four health factors affecting health outcomes. A review of the literature on this admittedly wide-ranging topic shows advantages and disadvantages depending on the subject under review. Recent evidence shows that rural areas in the United States have lower air pollution and nitrogen dioxide concentrations [24]. However, rural counties unsurprisingly have greater exposure to agriculture-related pollution than urban counties [25]. Asthma morbidity may also be worse for rural compared to urban patients [26]. With regard to the built environment, access to recreational facilities has been found to be associated with BMI levels. [27-29]. There is also evidence to suggest that some rural residents lack access to such facilities [30].

The CHR model's county health factors ultimately explain a county's health outcomes of mortality (length of life) and morbidity (quality of life). The literature on these two topics supports the causal relationship between factors and outcomes. The CHR uses years of potential life lost (YPLL) for the mortality outcome. The mortality rate for rural residents has been higher since at least 1968, although there appears to be some betterment of these numbers recently [31]. CDC data indicates that unintentional injuries contributing to death, such as poisoning, suffocation, and falls are more likely to occur in rural areas. Furthermore, the motor vehicle fatality rate for rural residents is believed to be almost double that of urban residents, attributed in part due to longer prehospital times $[32,33]$. Rural residents often have more hazardous occupations, a fact interconnected with social and economic factors, and experience delays in emergency response. Rural accident victims also have access to a lower number of healthcare facilities [9].

The morbidity outcome is based on health related quality of life and birth outcomes. Rural populations are more likely to have type 2 diabetes mellitus [34], and overall self-ratings of individual health decrease in rural areas [35]. The quality of life measure includes mental health. Research indicates that suicide rates, which affect YPLL, for both males and females were higher for those living in rural areas, with one study indicating rural men having twice the suicide rate when controlling for such variation as the divorce rate and ethnicity [36]. Children in rural areas are more likely to have behavioral and mental health problems as compared to their urban counterparts [37]. Access to mental health care can be limited in rural areas due to transportation problems, lack of reporting mental health issues, and a self-reliance that often includes self-care [38, 39]. When rural citizens do receive mental health treatment, the quality of clinical care has been questioned despite data indicating higher levels of need [40, 41].

The objective of this study was to determine whether differences in the $2013 \mathrm{CHR}$ indexed domains of health outcomes and their causal health factors exist between non-rural and rural counties. To our knowledge, this is the first study to examine differences in health outcomes between rural and nonrural counties utilizing CHR data. There are several benefits to using the CHR. As described above, the model incorporates a vast array of data covering numerous aspects related to the health of the U.S. population. Created by a credentialed team of scientists and public health experts, the rankings have been used by other researchers in peer-reviewed 
articles to study community health, mortality, and the implications on public policy $[42,43]$.

\section{Methods}

The authors have nothing to report regarding an ethics statement. Research was ruled exempt by the Essentia Health IRB, the IRB of authors TA and DS. The work did not meet the definition of research with human subjects, based on Office of Human Research Protections (OHRP) guidance.

We used publically accessible 2013 CHR county data ( $n=3053$ counties) which grouped counties into quartiles to "de-emphasize the differences between individual county ranks" [44]. Nearly all counties in the United States are ranked in their respective state based on publically available data. Data used in these rankings include health outcomes, which are a measure of premature mortality (deaths under age 75) and morbidity (overall, physical and mental health), both of which are predicted by health factors. CHR data from 2013 encompasses all counties with data available in the U.S. which are indexed into performance quartiles (where the first quartile are the top $25 \%$ of counties within each state, and the fourth quartile are the bottom $25 \%$ of counties within each state) and compared by the two geographic locales of non-rural $(n=1088)$ or rural $(n=1965)$. County ranks are based on computed and weighted composite scores within each state. A calculated weight represents the importance assigned by $\mathrm{CHR}$. The complete methodology associated with calculating the county ranks are available on the CHR website [44].

To determine if the geographic location of a county was rural or non-rural, the county was linked to a database containing the 2003 rural-urban county continuum codes developed by the Economic Research Service of the US Department of Agriculture [45]. We chose this taxonomy as it is commonly used for research [2]. The 2003 continuum codes form a classification scheme whose purpose is to distinguish metropolitan counties by size and non-metropolitan counties by degree of urbanization and proximity to metro areas. This urbanrural continuum scheme has nine categories for classifying US counties, three that are metropolitan and six that are non-metropolitan. In our analyses, the six nonmetro categories for counties were coded as rural and the three metro categories of counties were coded as non-rural [46].

Based on the CHR model described in Table 1, we used CHR's six indexed domains in our analysis (mortality and morbidity outcomes and the health factors of health behaviors, clinical care, social and economic factors, and physical environment). We first compared the six indexed domains between rural and non-rural counties using the chi-square test for significance at alpha level $5 \%$, where significance was set at $\mathrm{p} \leq 0.05$. We also used logistic regression analysis where the dependent variable was rural versus non-rural counties and the six domains accounted for the independent variables. A forward regression modelling strategy was used to determine those variables to be included in the final regression model. Adjusted and unadjusted estimated odds ratios are presented along with $95 \%$ confidence intervals. All analyses were performed using SPSS v.21 (SPSS Chicago, Ill).

\section{Results}

Overall, our analyses revealed health differences between rural and non-rural counties in the U.S. Table 2 shows the six indexed domains by quartile for rural and nonrural counties. Significant differences in each index were observed between rural and non-rural counties, with a greater proportion of rural counties in the fourth (worst) quartile. For example, among mortality, $31.5 \%$ of rural

Table 2 Indexed U.S. County Domain Quartiles by Geographic Locale 2013 U.S. County Health Rankings Data

\begin{tabular}{|c|c|c|c|c|}
\hline \multirow{2}{*}{$\begin{array}{l}\text { Indexed } \\
\text { Domains }^{\mathrm{a}}\end{array}$} & \multirow[t]{2}{*}{ Quartile $^{b}$} & \multicolumn{2}{|c|}{ Geographic Locale } & \multirow{2}{*}{$\begin{array}{l}P \text { value for } \\
\text { Chi Square }\end{array}$} \\
\hline & & $\begin{array}{l}\text { Rural } \\
n=1965\end{array}$ & $\begin{array}{l}\% \text { Non-Rural } \\
n=1087\end{array}$ & \\
\hline \multirow[t]{4}{*}{ Mortality } & 1 & 17.0 & 39.9 & \multirow[t]{4}{*}{$<.001$} \\
\hline & 2 & 24.9 & 26.3 & \\
\hline & 3 & 26.5 & 20.7 & \\
\hline & 4 & 31.5 & 13.1 & \\
\hline \multirow[t]{4}{*}{ Morbidity } & 1 & 22.1 & 30.8 & \multirow[t]{4}{*}{$<.001$} \\
\hline & 2 & 24.0 & 26.8 & \\
\hline & 3 & 24.8 & 24.4 & \\
\hline & 4 & 29.1 & 17.9 & \\
\hline \multirow{4}{*}{$\begin{array}{l}\text { Health } \\
\text { Behaviors }\end{array}$} & 1 & 19.3 & 35.8 & \multirow[t]{4}{*}{$<.001$} \\
\hline & 2 & 24.3 & 26.3 & \\
\hline & 3 & 28.4 & 17.8 & \\
\hline & 4 & 27.9 & 20.0 & \\
\hline \multirow[t]{4}{*}{ Clinical care } & 1 & 14.8 & 43.9 & \multirow[t]{4}{*}{$<.001$} \\
\hline & 2 & 24.3 & 26.2 & \\
\hline & 3 & 28.7 & 17.5 & \\
\hline & 4 & 32.2 & 12.3 & \\
\hline \multirow{4}{*}{$\begin{array}{l}\text { Social and } \\
\text { economic } \\
\text { factors }\end{array}$} & 1 & 18.1 & 38.0 & \multirow[t]{4}{*}{$<.001$} \\
\hline & 2 & 24.3 & 26.2 & \\
\hline & 3 & 27.2 & 20.1 & \\
\hline & 4 & 30.4 & 15.6 & \\
\hline \multirow{4}{*}{$\begin{array}{l}\text { Physical } \\
\text { environment }\end{array}$} & 1 & 25.2 & 25.2 & \multirow[t]{4}{*}{$=.002$} \\
\hline & 2 & 23.7 & 27.3 & \\
\hline & 3 & 23.9 & 26.1 & \\
\hline & 4 & 27.2 & 21.3 & \\
\hline
\end{tabular}

${ }^{\mathrm{a}}$ Each index is comprised of multiple variables that are given different weights ${ }^{\mathrm{b}}$ The first quartile is considered the best and the fourth the worst Source: Author 
counties and only $13.1 \%$ of non-rural counties were in the fourth quartile $(\mathrm{p}<0.001)$. Within the rural locale, there is also a gradient effect from the 1st quartile of mortality $(17.0 \%)$ to the 4th quartile of mortality $(31.5 \%)$. There is a similar gradient effect across most domains and for non-rural counties as well. Similarly, a significantly greater proportion of rural counties versus non-rural counties in the 4th quartile was observed for the morbidity ( $29.1 \%$ vs $17.9 \%$ ), health behaviors ( $27.9 \%$ vs $20.0 \%$ ), clinical care ( $32.2 \%$ vs $12.3 \%$ ), social and economic factors (30.4\% vs $15.6 \%$ ), and physical environment (27.2\% vs $21.3 \%$ ) domains.

Table 3 presents the results of a logistic regression model among rural counties for the indexed domains. For mortality, rural counties were at a significantly increased (estimated $\mathrm{OR}=3.110,95 \%$ CI 2.306, 4.195) odds of being in the worst quartile than the best. Rural counties were also at a significantly increased odds of being in the worst versus the best quartile for clinical care (estimated OR $=5.192,95 \%$ CI 4.001, 6.738) and social and economic factors (estimated OR $=1.792,95 \%$ CI 1.328, 2.419). However, rural counties were at significantly decreased odds of being in the worst versus the best quartile for morbidity (estimated OR $=0.71295 \%$ CI $0.531,0.955)$ and physical environment (estimated $\mathrm{OR}=0.70695 \%$ CI 0.555, 0.899).

\section{Discussion}

Our results demonstrate generally poorer mortality, clinical care, and social and economic outcomes for rural versus non-rural counties. Overall, rural counties were more likely to be in the fourth quartile of their respective states than non-rural counties. However, we also found that rural counties compared favorably to nonrural counties for the physical environment and morbidity domains. The largest differences between rural and non-rural counties were in the indexed domains mortality and clinical care. Rural counties had three times the odds of being in the 4th quartile of mortality than nonrural counties, and about five times the odds of being in

Table 3 Logistic Regression Model for Rural Geographic Locale of U.S. Counties by Indexed Domain Quartile 2013 U.S. County Health Rankings Data

\begin{tabular}{|c|c|c|c|}
\hline Indexed Domain & Quartile & Adjusted estimated odds ratio $(95 \% \mathrm{Cl})$ & Unadjusted estimated odds ratio (95\% Cl) \\
\hline \multirow[t]{4}{*}{ Mortality } & 1 & $-^{a}$ & $-^{\mathrm{a}}$ \\
\hline & 2 & $1.691(1.337,2.140)$ & $2.220(1.810,2.722)$ \\
\hline & 3 & $1.955(1.511,2.530)$ & $3.000(2.428,3.707)$ \\
\hline & 4 & $3.110(2.306,4.195)$ & $5.647(4.480,7.118)$ \\
\hline \multirow[t]{4}{*}{ Morbidity } & 1 & $-^{*}$ & $-^{*}$ \\
\hline & 2 & $.819(.646,1.037)^{b}$ & $1.245(1.015,1.527)$ \\
\hline & 3 & $.646(.498, .838)$ & $1.421(1.156,1.748)$ \\
\hline & 4 & $.712(.531, .955)$ & $2.264(1.824,2.811)$ \\
\hline \multirow[t]{4}{*}{ Health behaviors } & 1 & $-{ }^{a}$ & $-{ }^{a}$ \\
\hline & 2 & $1.028(.811,1.302)^{b}$ & $1.707(1.393,2.093)$ \\
\hline & 3 & $1.278(.981,1.666)^{b}$ & $2.950(2.377,3.661)$ \\
\hline & 4 & $.860(.649,1.140)^{b}$ & $2.578(2.087,3.184)$ \\
\hline \multirow[t]{4}{*}{ Clinical care } & 1 & $-{ }^{\mathrm{a}}$ & $-{ }^{\mathrm{a}}$ \\
\hline & 2 & $2.354(1.891,2.931)$ & $2.755(2.240,3.388)$ \\
\hline & 3 & $3.642(2.868,4.626)$ & $4.876(3.907,6.063)$ \\
\hline & 4 & $5.192(4.001,6.738)$ & $7.760(6.125,9.831)$ \\
\hline \multirow[t]{4}{*}{ Social and economic factors } & 1 & $--^{\mathrm{a}}$ & $-{ }^{\mathrm{a}}$ \\
\hline & 2 & $1.319(1.042,1.670)$ & $1.946(1.587,2.386)$ \\
\hline & 3 & $1.556(1.192,2.030)$ & $2.829(2.289,3.496)$ \\
\hline & 4 & $1.792(1.328,2.419)$ & $4.074(3.264,5.085)$ \\
\hline \multirow[t]{4}{*}{ Physical environment } & 1 & $--^{\mathrm{a}}$ & $--^{a}$ \\
\hline & 2 & $.741(.589, .932)$ & $.869(.706,1.069)^{b}$ \\
\hline & 3 & $.674(.534, .851)$ & $.914(.742,1.126)^{b}$ \\
\hline & 4 & $.706(.555, .899)$ & $1.276(1.031,1.580)$ \\
\hline
\end{tabular}

${ }^{\mathrm{a}}$ Reference category

${ }^{b}$ Estimated Odds Ratio not statistically significant

(Dependent variable is rural/non-rural classification of county) 
the 4th quartile of clinical care. In addition, the morbidity domain is comprised in part by mental health data, specifically the number of poor mental health days reported by a survey respondent. Given the research on mental health in rural populations, rural performance in this quartile may be surprising. It is possible that higher scores in the morbidity domain are attributable to other measurements outside of mental health. The difference in mortality found in rural counties may be attributable to a host of causes. One of the domains we believe may be a factor in driving the large difference in mortality is poorer access and worse quality of clinical care in rural counties. There is evidence to suggest that rural residents may also tend to delay the receiving of care, increasing the risk of a poorer health outcome [47] and have fewer providers of care [48].

A lack of healthy eating habits may also be attributable to increases in mortality in rural areas. This could possibly be due to a lack of healthier, low cost eating options [49]. In part because of travel restrictions and cost, rural residents may be more likely to buy food at convenience stores rather than at conventional stores such as supermarkets. "Food deserts," areas of the country where residents have less access to affordable and healthful food tend to be in rural areas although they can also be present in highly urban populations [50,51].

Rural counties were also at greater odds of being in the fourth quartile of the social and economic factor domain. This domain in part uses motor vehicle injury data and research has found that rural residents are less likely to survive motor vehicle accidents, in part due to access restrictions $[52,53]$. The domain also takes into account education, employment and income factors, where it was found that residents in rural counties were at the lower end on these measurements.

\section{Limitations}

On a conceptual level, there is a lack of agreement between invested parties on what 'rural' means and how the term should be defined and measured. This creates problems for policymakers and the health-care providing community [2]. Standardizing the definition and measurement of rurality is a difficult task and likely impossible given the variety of interests on how the terms should be used. The U.S. federal government has multiple definitions for the term [2]. Scholars should choose definitions in line with their research question and available data and resources.

Another limitation is that the CHR does not take into account all possible factors that determine community health. For example, the physical environment domain encompasses multiple factors (air pollution, water quality, the built environment), but it of course does not and cannot account for all possible components that could make up one's definition of the physical environment. The conceptual framework of the health factors and outcomes are certainly open to critique, and therefore some caution must be used when making statements about study results. However, given the problem of limitations caused by infrequent data reporting or unavailability for certain regions, we believe the CHR team has compiled a respectable dataset. Ultimately, CHR was able to compile data from more than $97 \%$ of all counties in the US.

As this paper is a cross-sectional study, causality cannot be confirmed. Furthermore, the methodology for this paper divided counties into four quartiles based on each state's quartile rankings. This means that counties in one state may have overall poorer health than counties in other states that have the same quartile rankings. There may be an argument against using quartiles and instead using natural breaks in the entire US county dataset where quartiles are set a-priori, and only counties meeting a predetermined threshold would fall in each quartile making nationwide studies possible. While perhaps problematic in certain respects, the data limitations do not prevent the production of meaningful observations and results.

\section{Conclusion}

Ultimately, our results indicate that there are significant differences in the overall health and health outcomes of rural populations as compared to urban populations. Populations in rural counties tended to score below their non-rural peers in the six indexed domains of health measured by the CHR, although the results of our logit regression indicate better performance for rural counties in physical environment and morbidity scores. This research furthers the evidence of the divide in health and healthcare between the observed rural and non-rural populations. We believe public health professionals and policy makers in the US must continue to consider these differences when implementing programs addressing the needs of a geographically diverse population.

\section{Competing interests}

TA and DS are both employees of EIRH, which is a member of BioMed Central. MNL is an employee of the University of Minnesota, which is a supporting member of BioMed Central.

MSL has no competing interests to declare.

\section{Authors' contributions}

TA, DS and MNL contributed equally to study design, data analysis, manuscript preparation and approval. Author MSL contributed to the conceptualization of this study as well as data discussion. All authors read and approved the final manuscript.

Authors' information

Not applicable.

Availability of data and materials

Not applicable. 


\section{Acknowledgements}

The authors have no acknowledgements. All work was done by the authors in their respective work duties. No funding bodies contributed to any aspect of this work.

\section{Author details}

${ }^{1}$ Essentia Institute of Rural Health, 502 E. 2nd Street, Duluth, MN 55805, USA. ${ }^{2}$ National Center for Interprofessional Practice and Education, University of Minnesota-Twin Cities Campus, MMC 501 Mayo, 420 Delaware St SE, Minneapolis, MN 55455, USA. ${ }^{3}$ Roseman University of Health Sciences, 10920 S. River Front Parkway, South Jordan, UT 84095, USA.

Received: 19 November 2014 Accepted: 11 September 2015 Published online: 01 October 2015

\section{References}

1. Lutfiyya MN, McCullough JE, Haller IV, Waring SC, Bianco JA, Lipsky MS Rurality as a root or fundamental social determinant of health. Dis Mon. 2012;58:620-8.

2. Gary HL, Larson EH, Lishner DM. Rural definitions for health policy and research. Am J Public Health. 2005;95:1149.

3. Johnson MEB, Warner C, Roberts LW, TD. Rural-urban health care provider disparities in Alaska and New Mexico. Adm Policy Ment Health. 2006;33:504-7.

4. Joynt KE, Harris Y, Orav EJ, Jha AK. Quality of care and patient outcomes in critical access rural hospitals. JAMA. 2011;306(1):45-52.

5. Ingram DD, Franco SJ. 2013 NCHS urban-rural classification scheme for counties. National Center for Health Statistics. Vital Health Stat. 2014;2:166.

6. 3D National Center for Health Statistics. Health, United States, 2013: With Special Feature on Prescription Drugs. Hyattsville, MD. 2014.

7. Cummins $S$ et al. Understanding and representing 'place' in health research: a relational approach. Soc Sci Med. 2007;65(9):1825-38.

8. University of Wisconsin Population Health Institute. County Health Rankings 2013. Available at www.countyhealthrankings.org. Accessed 5/1/2014.

9. Health, United States, 2001. Urban and rural health chartbook. In: Department of Health and Human Services, Centers for Disease Control and Prevention, National Center for Health Statistics. 2001.

10. Lutfiyya MN et al. Adolescent daily cigarette smoking: is rural residency a risk factor? Rural Remote Health. 2008;8(1).

11. Lutfiyya, M N, Lipsky, M S, Wisdom-Behounek, J and Inpanbutr-Martinkus, M. Is rural residency a risk factor for overweight and obesity for U.S. children? 2007 North American Association for the Study of Obesity (NAASO). Issue. Obesity 2007; Volume 15, Issue 9, pages 2348-2356.

12. Befort CA, Nazir N, Perri MG. Prevalence of obesity among adults from rural and urban areas of the United States: findings from NHANES 2005-2008. J Rural Health. 2012;28(4):392-7.

13. Lutfiyya MN, Chang LF, Lipsky MS. A cross-sectional study of US rural adults' consumption of fruits and vegetables: do they consume at least five servings daily? BMC Public Health. 2012;12:280.

14. Borders TF, Booth Brenda M. Rural, suburban, and urban variations in alcohol consumption in the United States: findings from the National Epidemiologic Survey on Alcohol and Related Conditions. The. J Rural Health. 2007:23(4):314-21

15. Martin Sarah $L$ et al. Urban, rural, and regional variations in physical activity. J Rural Health. 2005;21(3):239-44.

16. Eberhardt MS, Elsie PR. The importance of place of residence: examining health in rural and non-rural areas. Am J Public Health. 2004;94(10):1682-6.

17. Saman DM, Johnson AO, Arevalo O, Odoi A. Geospatially illustrating regional-based oral health disparities in Kentucky. Public Health Rep. 2011;126(4):612-8

18. Rural Assistance Center. Rural health disparities. 2009. Available at www.raconline.org/topics/rural-health-disparities. Accessed 2/1/2015.

19. Stranges, E., Stocks, C. Potentially preventable hospitalizations for acute and chronic conditions, 2008. 2010; Statistical Brief \#99 from NIH Healthcare Cost and Utilization Project.

20. Byun Soo-yong J, Irvin M, Meece JL. Predictors of bachelor's degree completion among rural students at four-year institutions. Rev High Educ. 2012;35:3.

21. Byun Soo-yong J, Irvin M, Meece JL. Rural-nonrural disparities in postsecondary educational attainment revisited. Am Educ Res J. 2012;49(3):412-37
22. Jordan JL, Genti K, Mykerezi E. Rural and urban high school dropout rates: Are they different? J Res Rural Educ. 2012;27(12):1-21.

23. Brown DL, Swanson LE (Eds), Challenges for rural America in the twenty-first century. Rural poverty: the persisting challenge. Pennsylvania University Press, University Park PA 2003; 118-131.

24. Clark LP, Millet DB, Marshall JD. National patterns in environmental injustice and inequality: outdoor NO2 air pollution in the United States. PLoS One. 2014;9(4):e94431.

25. Hendryx M, Fedorko E, Halverson J. Pollution sources and mortality rates across rural-urban areas in the United States. J Rural Health. 2010;26(4):383-91.

26. Pesek RD, Vargas PA, Halterman JS, Jones SM, McCracken A, Perry $\Pi$. A comparison of asthma prevalence and morbidity between rural and urban schoolchildren in Arkansas. Ann Allergy Asthma Immunol. 2010;104(2):125-31.

27. Maroko AR, Maantay JA, Sohler NL, Grady KL, Arno PS. The complexities of measuring access to parks and physical activity sites in New York City: a quantitative and qualitative approach. Int J Health Geogr. 2009;8:34.

28. Boehmer TK, Lovegreen SL, Haire-Joshu D, Brownson RC. What constitutes an obesogenic environment in rural communities? Am J Health Promot. 2006;20(6):411-21.

29. Pitts $S$, Jilcott $B$, et al. Obesity is inversely associated with natural amenities and recreation facilities per capita. J Phys Act Health. 2013;10:1032-8.

30. Edwards ME, Jilcott SB, Moore JB, Floyd M. County level disparities in access to recreational resources and associations with adult obesity in North Carolina. J Park Recreat Admi. 2011;29(2):39-54.

31. James WL. All rural places are not created equal: revisiting the rural mortality penalty in the United States. Am J Public Health. 2014;104(11):2122-9.

32. González RP et al. Does increased emergency medical services prehospital time affect patient mortality in rural motor vehicle crashes? A statewide analysis. Am J Surg. 2009;197:30-4.

33. Gonzalez RP et al. Improving rural emergency medical service response time with global positioning system navigation. J Trauma Acute Care Sur. 2009;67(5):899-902.

34. Krishna S, Gillespie KN, McBride TM. Diabetes Burden and Access to Preventive Care in the Rural United States. J Rural Health. 2010;26:3-11.

35. Bethea TN, Lopez RP, Cozier YC, White LF, McClean MD. The relationship between rural status, individual characteristics, and self-rated health in the behavioral risk factor surveillance system. J Rural Health. 2012;28:327-38.

36. Singh GK, Mohammad S. Increasing rural-urban gradients in US suicide mortality, 1970-1997. Am J Public Health. 2002;92(7):1161-7.

37. Lenardson JD et al. Access to mental health services and family impact of rural children with mental health problems. Rural Health Res Policy Centers. 2010;45:1-15.

38. Human J, Cathy W. Rural mental health in America. Am Psychol. 1991;46(3):232.

39. Skinner, Asheley C, Slifkin RT. Rural/urban differences in barriers to and burden of care for children with special health care needs. J Rural Health. 2007;23(2):150-7.

40. Ziller EC, Anderson NJ, Coburn AF. Access to rural mental health services: service use and out-of-pocket costs. J Rural Health. 2010;26(3):214-24.

41. Health insurance coverage in rural America: Chartbook. University of Southern Maine, Muskie School of Policy Service, Institute of Health Policy, 2003.

42. Peppard PE et al. Ranking community health status to stimulate discussion of local public health issues: the Wisconsin County Health Rankings. Am J Public Health. 2008;98(2):209.

43. Rohan AMK, Booske BC, Remington PL. Using the Wisconsin County Health Rankings to catalyze community health improvement. J Public Health Manag Pract. 2009;15(1):24-32.

44. County Health Rankings and Roadmaps. Calculating scores and ranks. Available at http://www.countyhealthrankings.org/ranking-methods/ calculating-scores-and-ranks. Accessed 5/1/2014.

45. United Stated Department of Agriculture. Economic Research Service. Overview. Available at http://www.ers.usda.gov/data-products/rural-urban-continuumcodes.aspx. Accessed 5/1/2014.

46. United Stated Department of Agriculture. Economic Research Service. Rural-urban continuum codes, 2003. Available at http://webarchives. cdlib.org/wayback.public/UERS_ag_1/20110913215738/http://www.ers. usda.gov/Briefing/Rurality/RuralUrbCon/RuralUrbanCont2003.gif. Accessed 2/1/2015. 
47. Ricketts TC. The changing nature of rural health care. Annu Rev Public Health. 2000;21(1):639-57.

48. Gary HL et al. Rural health care providers in the United States. J Rural Health. 2002;18(5):211-31.

49. Liese $A D$ et al. Food store types, availability, and cost of foods in a rural environment. J Am Diet Assoc. 2007;107(11):1916-23.

50. Hendrickson D, Smith C, Eikenberry N. Fruit and vegetable access in four low-income food deserts communities in Minnesota. Agricul Human Values. 2006;23:371-83.

51. Smith C, Morton LW. Rural food deserts: low-income perspectives on food access in Minnesota and lowa. J Nutr Educ Behav. 2009;41(3):176-87.

52. Travis $L L$ et al. Mortality in rural locations after severe injuries from motor vehicle crashes. J Safety Res. 2012;43(5):375-80. 290.

53. Chang DC et al. Density of surgeons is significantly associated with reduced risk of deaths from motor vehicle crashes in US counties. J Am Coll Surg. 2011;212(5):862-6.

\section{Submit your next manuscript to BioMed Central and take full advantage of:}

- Convenient online submission

- Thorough peer review

- No space constraints or color figure charges

- Immediate publication on acceptance

- Inclusion in PubMed, CAS, Scopus and Google Scholar

- Research which is freely available for redistribution 